bladder cancer than for lung cancer such cases might be expected." I have two such patients whose abbreviated case histories are here reported.

A man born in 1902 smoked $85 \mathrm{~g} \mathrm{(3oz)} \mathrm{of}$ tobacco per week, making his own cigarettes. He had a right pneumonectomy for squamous cell carcinoma in 1957. He remained fairly well and at work until 1966, when he was found to have a hiatus hernia. This was repaired surgically. In 1971 he developed haematuria which was shown to be due to a well-differentiated transitional cell carcinoma of bladder. This was treated with a radical course of radiotherapy, 6000 rads in 42 days, with an excellent result. He is still alive.

A man born in 1895 smoked 20 cigarettes a day from 1917 to 1938 and then a pipe. A right middle and lower lobectomy was done in 1961 for an anaplastic carcinoma of lung. In May 1971 he had haematuria and cystoscopy showed a carcinoma of bladder. A satisfactory biopsy specimen was not obtained. It was treated by cystodiathermy. In November 1973 new opacities developed in the right lung, the largest being $3.5,6 \mathrm{~cm}$. These were considered to be metastases from the bladder carcinoma. They increased in size and he died in May 1975.

T A W EDWARDS

Chest Clinic,

St Albans City Hospital

St Albans, Herts

\section{Staffing in hospital laboratories}

SIR,-Those of your readers who have not had an opportunity to scudy the policy statement of the Institute of Medical Laboratory Sciences on future staffing in the medical laboratory service will have gained a totally erroneous impression of the document from the letter you published from consultant pathologists in the Trent Region (12 February, p 441).

The implication of that letter seemed to be that the institute in its policy statement recognised no place for medically qualified staff; the institute's assumption, however, was that it was inappropriate to consider them in the same context as non-medical staff. As the first paragraph of the policy statement pointed out, medical staff were therefore excluded from the subsequent discussion. The statement did include, however, arguments for integrating the "scientific" and "technical" staff of laboratories as the distinction between the two is becoming increasingly artificial on grounds of either function or qualification. Those who work in medical laboratories will know just how trivial is the difference in function and, as the institute's evidence to the Royal Commission on the NHS pointed out, more graduates are now entering the "technician" class than are entering as "scientists." In these circumstances the distinction which the authors of the letter try to make between graduates and technicians does not bear examination.

Your correspondents choose to attack the policy statement as containing "many assumptions and inaccuracies" but fail to quote a single example. In contrast, inaccuracies can be demonstrated in their letter: two in the first sentence. This institute was formerly known as the Institute of Medical Laboratory Technology, not Technicians, and the title and content of our policy statement referred to staffing in the medical laboratory service, not of the service as your correspondents claimed. The institute observed this important distinction by deliberately refraining from comment on the medical staffing of hospital laboratories; the courtesy of reciprocation would have been appreciated.

There has been no evidence during the months since publication of the policy statement to justify its condemnation as "a divisive document which could sour the currently good relations built up over the years between all grades of laboratory staff"perhaps because most readers did not misinterpret it. Good relations in the service will not be encouraged by a letter inciting others to inflammatory correspondence. In the interest of the medical laboratory service it would have been better left unwritten.

$$
\begin{array}{r}
\text { F J BAKER } \\
\text { President, } \\
\text { J K FAWCETT } \\
\text { Secretary, } \\
\text { Faboratory Sciences }
\end{array}
$$

London $\mathrm{W} 1$

authors refer to the paper they quote they will see that it describes the use of vidarabine in two cases of severe chickenpox in adults and the use of the drug in that extremely rare condition purpura fulminans in zoster.

Bent Juel-Jensen

Department of the Regius Professor

of Medicine,

Radcliffe Infirmary,

Juel-Jensen, B E, and MacCallum, F O, Herpes Simplex, Varicella and Zoster. London, Heinemann,

1972 .
Juel-Jensen, B E, fournal of Antimicrobial Chemotherapy, 1976, 2, 261.

therapy, In E E, fournal of Antimicrobial Chemotherapy, In press.

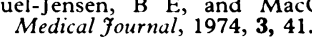

\title{
Royal College of General Practitioners
}

\section{Chemotherapy for varicella-zoster}

\section{infections}

SIR,-Dr R P R Dawber (29 January, p 286) makes a number of dogmatic statements which should not go unchallenged. MacCallum and $I^{1}$ recommended cytarabine and vidarabine in the treatment of severe zoster in our book five years ago. We did not refer to clinical trials because there had not been any at that stage. The drugs were quite new. In the case reports that gave rise to your leading article (18 December, p 1466) I actually tried to measure the fate of the virus when it was treated with the antiviral drug and this, as well as recording the clinical course, is probably as much as one can hope to do in rare and life-threatening conditions like purpura fulminans in zoster. It is difficult or impossible to get enough patients with severe herpes simplex and varicella zoster manifestations to make a double-blind controlled trial possible. The best one can hope for often is to monitor the virus shedding. have given examples of this elsewhere. ${ }^{3}$ A double-blind controlled trial on the relative merits of cytarabine and idoxuridine in uncomplicated zoster is in progress at the moment.

I agree with Dr Dawber that the reason for treating even uncomplicated segmental zoste is not only to deal with the immediate problem of pain but with postherpetic neuralgia. I do not agree with his statements about the concentration of idoxuridine to be used MacCallum and $\mathrm{I}^{\prime}$ have already pointed out that a $35^{\circ}$. solution of idoxuridine in dimethyl sulphoxide (DMSO) is more effective than a $20^{\circ}{ }_{0}$ solution, and that in turn more effective than a $5^{\circ}$ " solution. I have treated in excess of 2000 patients and less than $5^{\prime}{ }_{n}$ get severe histamine reaction from the DMSO. In none have there been necrotic skin changes. If bought in bulk idoxuridine is not very expensive and the cost of treating the averag patient with zoster by continuous topical application of a $35^{\circ}$, solution, which I now use, varies between $£ 15$ and $£ 30$ depending on the extent of the lesion. The number of admissions for zoster to the infectious disease unit has dropped to about one-twentieth of what it used to be before there was an active treatment available, so the outlay on drugs is paid for many times over by keeping people out of hospital.

Dr P A M Walden and others (BMF, 5 February, p 378) state that I have reported "a good clinical response in two out of three cases with herpes zoster infections." "If the

SIR,-Many founder members of the Royal College of General Practitioners must have been very depressed by Dr I Capstick's Personal View (5 February, p 373). After two years in resident posts I entered general practice early in 1930 because I wanted to deal with "people" and not just to treat "cases" with various anatomical and physiological defects. After some years (seven as secretary of a BMA division) I realised that standards in general practice varied enormously and I was proud to join a professional body that was concerned solely with the standards and quality of work in general practice-a body that was able to contradict Lord Moran's statement that "GPs were the doctors who had fallen off the hospital promotion ladder." Our college has done this.

If general practice is to be recognised as a specialty in its own right our college must behave as the other royal colleges have done. No doctor can become a full consultant now without a higher qualification (FRCS, MRCP, MRCOG). Our college should press the authorities to rule that no doctor can become a full partner or unsupervised singlehanded GP without the MRCGP diploma.

Since retiring at the end of 1968 I have been saddened to see how mercenary the profession has become. The idea of doctors arguing like dockers about hours of work and overtime pay appals me. But if the younger generation want it that way we cannot stop them. They have been taking the DRCOG because it gave them higher fees in the NHS. If the MRCGP will do the same they will take that too. At least we shall know that they have achieved a certain standard of knowledge. But in the years to come I wonder if their old patients will send them Christmas cards and come down to visit them, as some of mine still do.

Matfield, Kent

A S HATCH

SIR,-To judge from his writings in your columns and elsewhere Dr D R Cargill (19 February, p 508) does not always appear to view with detachment the postgraduate scene in relation to general practice. However, he has a point in emphasising the need to seek out the professional and informed views of general practitioners concerning vocational training.

This letter seeks to draw attention to a survey, conducted with support from the Royal College of General Practitioners and the Scottish General Medical Services Committee. 